Louisiana State University

LSU Digital Commons

5-1-2006

\title{
Comparing tropical forest tree size distributions with the predictions of metabolic ecology and equilibrium models
}

\author{
Helene C. Muller-Landau \\ University of Minnesota Twin Cities \\ Richard S. Condit \\ Smithsonian Tropical Research Institute \\ Kyle E. Harms \\ Smithsonian Tropical Research Institute \\ Christian O. Marks \\ University of Minnesota Twin Cities \\ Sean C. Thomas \\ University of Toronto
}

See next page for additional authors

Follow this and additional works at: https://digitalcommons.Isu.edu/biosci_pubs

\section{Recommended Citation}

Muller-Landau, H., Condit, R., Harms, K., Marks, C., Thomas, S., Bunyavejchewin, S., Chuyong, G., Co, L., Davies, S., Foster, R., Gunatilleke, S., Gunatilleke, N., Hart, T., Hubbell, S., Itoh, A., Kassim, A., Kenfack, D., LaFrankie, J., Lagunzad, D., Lee, H., Losos, E., Makana, J., Ohkubo, T., Samper, C., Sukumar, R., Sun, I., Nur Supardi, M., Tan, S., Thomas, D., Thompson, J., Valencia, R., Vallejo, M., \& Muñoz, G. (2006). Comparing tropical forest tree size distributions with the predictions of metabolic ecology and equilibrium models. Ecology Letters, 9 (5), 589-602. https://doi.org/10.1111/j.1461-0248.2006.00915.x

This Article is brought to you for free and open access by the Department of Biological Sciences at LSU Digital Commons. It has been accepted for inclusion in Faculty Publications by an authorized administrator of LSU Digital Commons. For more information, please contact ir@lsu.edu. 


\section{Authors}

Helene C. Muller-Landau, Richard S. Condit, Kyle E. Harms, Christian O. Marks, Sean C. Thomas, Sarayudh Bunyavejchewin, George Chuyong, Leonardo Co, Stuart Davies, Robin Foster, Savitri Gunatilleke, Nimal Gunatilleke, Terese Hart, Stephen P. Hubbell, Akira Itoh, Abd Rahman Kassim, David Kenfack, James V. LaFrankie, Daniel Lagunzad, Hua Seng Lee, Elizabeth Losos, Jean Remy Makana, Tatsuhiro Ohkubo, Cristian Samper, Raman Sukumar, I. Fang Sun, M. N. Nur Supardi, Sylvester Tan, Duncan Thomas, Jill Thompson, Renato Valencia, Martha Isabel Vallejo, and Gorky Villa Muñoz 


\section{LETTER}

\section{Comparing tropical forest tree size distributions with the predictions of metabolic ecology and equilibrium models}

Helene C. Muller-Landau, ${ }^{1}$ * Richard S. Condit, ${ }^{2}$ Kyle E. Harms, ${ }^{2,3}$ Christian 0. Marks, ${ }^{1}$

Sean C. Thomas, ${ }^{4}$ Sarayudh Bunyavejchewin, ${ }^{5}$ George Chuyong, ${ }^{6}$ Leonardo $\mathrm{Co}^{7}{ }^{7}$ Stuart Davies, ${ }^{2}$ Robin Foster, ${ }^{8}$ Savitri Gunatilleke, ${ }^{9}$ Nimal Gunatilleke, ${ }^{9}$ Terese Hart, ${ }^{10}$ Stephen P. Hubbell, ${ }^{2,11}$ Akira Itoh, ${ }^{12}$ Abd Rahman Kassim, ${ }^{13}$ David Kenfack, ${ }^{14}$ James V. LaFrankie, ${ }^{15}$ Daniel Lagunzad, ${ }^{16}$ Hua Seng Lee, ${ }^{17}$ Elizabeth Losos, ${ }^{18}$ JeanRemy Makana, ${ }^{19}$ Tatsuhiro Ohkubo, ${ }^{20}$ Cristian Samper, ${ }^{21}$ Raman Sukumar, ${ }^{22}$ I-Fang Sun, ${ }^{23}$ Nur Supardi M. N., ${ }^{24}$ Sylvester Tan, ${ }^{25}$ Duncan Thomas, ${ }^{26}$ Jill Thompson, ${ }^{27}$ Renato Valencia, ${ }^{28}$ Martha Isabel Vallejo, ${ }^{29}$ Gorky Villa Muñoz, ${ }^{28}$ Takuo Yamakura, ${ }^{30}$ Jess $\mathrm{K}$. Zimmerman, ${ }^{27}$ Handanakere Shivaramaiah Dattaraja, 22 Shameema Esufali, ${ }^{11}$ Pamela Hall, $^{31}$ Fangliang $\mathrm{He}^{32}$ Consuelo Hernandez, ${ }^{28}$ Somboon Kiratiprayoon, ${ }^{33}$ Hebbalalu S. Suresh, ${ }^{22}$ Christopher Wills ${ }^{34}$ and Peter Ashton ${ }^{35}$

\begin{abstract}
Tropical forests vary substantially in the densities of trees of different sizes and thus in above-ground biomass and carbon stores. However, these tree size distributions show fundamental similarities suggestive of underlying general principles. The theory of metabolic ecology predicts that tree abundances will scale as the -2 power of diameter. Demographic equilibrium theory explains tree abundances in terms of the scaling of growth and mortality. We use demographic equilibrium theory to derive analytic predictions for tree size distributions corresponding to different growth and mortality functions. We test both sets of predictions using data from 14 large-scale tropical forest plots encompassing censuses of 473 ha and $>2$ million trees. The data are uniformly inconsistent with the predictions of metabolic ecology. In most forests, size distributions are much closer to the predictions of demographic equilibrium, and thus, intersite variation in size distributions is explained partly by intersite variation in growth and mortality.
\end{abstract}

\section{Keywords}

Demographic rates, forest structure, large-scale disturbance, metabolic theory of ecology, old-growth forests, tree diameter distributions.

Ecology Letters (2006) 9: 589-602

\footnotetext{
${ }^{1}$ Department of Ecology, Evolution and Behavior, University of Minnesota, 1987 Upper Buford Circle, St Paul, MN 55108, USA ${ }^{2}$ Smithsonian Tropical Research Institute, Unit 0948, APO AA 34002-0948, Miami, FL, USA

${ }^{3}$ Department of Biological Sciences, Louisiana State University, 202 Life Sciences Building, Baton Rouge, LA 70803-1715, USA ${ }^{4}$ Faculty of Forestry, University of Toronto, 33 Willcocks St, Toronto, ON, Canada

${ }^{5}$ National Parks Wildlife and Plant Conservation Department, Research Office, 61 Paholyothin Road, Chatuchak, Bangkok 10900, Thailand
}

\author{
${ }^{6}$ Department of Life Sciences, University of Buea, PO Box 63, \\ Buea, Cameroon \\ ${ }^{7}$ Institute of Biology, College of Science, University of the \\ Philippines, Herbarium, Diliman 1101, Quezon City, Philippines \\ ${ }^{8}$ The Field Museum, 1400 S. Lake Shore Drive, Chicago, IL \\ 60605-2496, USA \\ ${ }^{9}$ Department of Botany, Faculty of Science, University of Pera- \\ deniya, Peradeniya 20400, Sri Lanka \\ ${ }^{10}$ Wildlife Conservation Society, International Programs, 185th \\ St and Southern Blvd, Bronx, NY 10460, USA
}


${ }^{11}$ Department of Plant Biology, University of Georgia, Athens, GA 30602, USA

${ }^{12}$ Laboratory of Plant Ecology, Graduate School of Science, Osaka City University, Osaka 558-8585, Japan

${ }^{13}$ Forest Management and Ecology Program, Forestry and Conservation Division, Forest Research Institute Malaysia, Kepong 52109, Selangor, Malaysia

${ }^{14}$ International Center for Tropical Ecology, University of Missouri Saint Louis, 8001 Natural Bridge Ave., St Louis, MO 63121, USA

${ }^{15}$ Center for Tropical Forest Science-Arnold Arboretum Asia Program, Nanyang Technological University, 1 Nanyang Walk, Singapore 637617, Singapore

${ }^{16}$ Faculty of Forestry, University of the Philippines, Diliman, Quezon City 1101, Philippines

${ }^{17}$ Sarawak Forest Department, Jalan Stadium, Petra Jaya, Kuching, Sarawak 93660, Malaysia

${ }^{18}$ Organization for Tropical Studies, Duke University, Durham, NC, USA

${ }^{19}$ Wildlife Conservation Society - DR Congo Program, Chanic Building, 2nd Floor, Ngaliema, PO Box 240, Kinshasa I, Democratic Republic of Congo

${ }^{20}$ Department of Forest Science, Utsunomiya University, 350

Minemachi, Utsunomiya 321-8505, Japan

${ }^{21}$ National Museum of Natural History, Smithsonian Institution, Washington, DC, USA

${ }^{22}$ Center for Ecological Science, Indian Institute of Science, Bangalore 560012, India

${ }^{23}$ Center for Tropical Ecology and Biodiversity, Tunghai

University, Taichung 40704, Taiwan

\section{INTRODUCTION}

Tropical forests vary widely in their structure and aboveground biomass (Ashton \& Hall 1992; Ter Steege et al. 2003), differences attributable mainly to wide variation in the density of large trees (Chave et al. 2001). However, their tree size distributions show fundamental similarities that suggest general underlying principles (Coomes et al. 2003). Given that tropical forests hold almost half of all aboveground carbon stores in the biosphere (Dixon et al. 1994), we cannot hope to understand the terrestrial carbon budget without an understanding of tropical forest tree size distributions. Recently, the theory of metabolic ecology has generated specific predictions about the functional form of this relationship (Enquist \& Niklas 2001) and its variation among sites (Niklas et al. 2003). Such a general theory could potentially advance fundamental understanding of forest structure and provide a basis for understanding current changes and predicting future changes in forest structure
${ }^{24}$ Forest Ecology Unit, Forestry and Conservation Division, Forest Research Institute Malaysia, Kepong 52109 Selangor, Malaysia

${ }^{25}$ Forest Research Center, KM 10 Jalan Datuk Amar Kalong Ningkan, 93250 Kuching, Sarawak, E., Malaysia

${ }^{26}$ Department of Forest Science, Oregon State University, 529 NW 31st Street, Corvallis, OR 97330, USA

${ }^{27}$ Institute for Tropical Ecosystem Studies, University of Puerto Rico Río Piedras, Box 21910, San Juan, PR 00931-1910, USA

${ }^{28}$ Herbario QCA. Dept. de Ciencias Biológicas, Pontificia Universidad Católica del Ecuador, Aptado. 17-01-2184, Quito, Ecuador

${ }^{29}$ Instituto Alexander von Humboldt, Ministerio del Medio Ambiente, Calle 37 no. 8-40 Mezzanine, Bogota, Colombia ${ }^{30}$ Department of Biology, Faculty of Science, Osaka City University, Sugimoto, Sumiyoshi-ku, Osaka 558-8585, Japan ${ }^{31}$ Department of Biological Sciences, Florida State University, Tallahassee FL 32306-4370, USA

${ }^{32}$ Department of Renewable Resources, University of Alberta, Edmonton, AB, Canada T6G $2 \mathrm{H} 1$

${ }^{33}$ Department of Environmental Science, Faculty of Science and Technology, Thammasat University (Rangsit), Patumtani, Thailand

${ }^{34}$ Division of Biological Sciences, University of California, San Diego, La Jolla, CA 92093-0116, USA

${ }^{35}$ Center for Tropical Forest Science-Arnold Arboretum Asia Program, 22 Divinity Avenue, Cambridge, MA 02138, USA

*Correspondence: E-mail: hmuller@umn.edu

and associated carbon pools (Baker et al. 2004; Wright 2005).

The metabolic theory of ecology strives to explain ecological structure by considering how the metabolic rates of organisms vary with body size and environmental conditions because of fundamental physical and chemical constraints (Brown et al. 2004). The seminal paper by West et al. (1997) derives the scaling of metabolic rates (gross photosynthetic rates in plants) with size from consideration of the limits on maximal rates of resource redistribution through the organism via fractal branching networks. By adding the assumptions that plants grow until they are limited by resources and that resource use is proportional to metabolic rate, Enquist et al. (1998) obtain a prediction for the scaling of plant density across plant communities varying in mean plant mass. This is essentially a self-thinning law, albeit one that predicts an exponent of $-4 / 3$ rather than the traditional $-3 / 2$ for the relationship between individual plant biomass and the density of plants across plant stands. 
Enquist \& Niklas (2001) state that this model also applies within stands, and thus turn it into a prediction for plant size distributions within old growth, and presumably equilibrium, communities.

Alternatively, equilibrium plant size distributions can be understood as the simple demographic consequence of sizedependent variation in growth and mortality (Coomes et al. 2003; Kohyama et al. 2003). Because mortality removes trees from size classes, increasing mortality in a given size class reduces the number of trees in that size class. Because growth moves trees from one size class to another and thus is inversely related to residence time within a size class, an increase in growth in a size class will also reduce the number of trees in that size class and increase the number in the next larger size class (Condit et al. 1998; Wright et al. 2003). Mathematically, the general relationship between size and age distributions, growth, and mortality is given by the von Foerster equation (Von Foerster 1959; Sinko \& Streifer 1967) which has long been an important tool in fisheries management (e.g. Ebert et al. 1993; Smith et al. 1998). At demographic equilibrium, size distributions are determined completely by the functions relating average growth and mortality to size (Kohyama et al. 2003). Thus, for example, exponential size distributions are expected if absolute growth rate and mortality rate are both size independent (Coomes et al. 2003).

Tests of the predictions of the metabolic ecology and demographic equilibrium models against whole-community tree size distributions have had mixed results to date. Enquist \& Niklas (2001) found support for their metabolic prediction of tree size distribution scaling in a data set from tropical forests. However, their criteria for excluding data bias their analyses, and a reanalysis of the same data set without this bias showed consistent deviations from the prediction at large tree sizes (Coomes et al. 2003). Coomes et al. (2003) also analysed a large data set from New Zealand temperate forests, again finding consistent deviations from metabolic ecology predictions. In contrast, Coomes et al. (2003) found support for the demographic equilibrium model in both tropical and temperate forest data sets.

If forests are at demographic equilibrium, then the equilibrium model makes it possible to precisely link functions describing size-dependent growth and mortality - including those proposed by the theory of metabolic ecology - to functions describing tree size distributions. Foresters regularly use quantitative descriptions of tree diameter distributions as indicators of management impacts and successional status (Goff \& West 1975; Goodburn \& Lorimer 1999; Schwartz et al. 2005). Further, several studies have previously simulated equilibrium diameter distributions in mixed-aged forests on the basis of size-dependent growth and mortality (e.g. Lorimer \& Frelich 1984; Kohyama 1991). However, although foresters have long used a variety of statistical models to quantitatively describe tree diameter distributions, including the negative exponential (DeLiocourt 1898; Meyer \& Stevenson 1943; Leak 1964; Moser 1972) and the two-parameter Weibull (Bailey \& Dell 1973), these and other theoretical diameter distributions have neither previously been derived directly from size-dependent growth and mortality, nor have their parameters been linked quantitatively to parameters describing growth and mortality.

Here, we first concisely state the logic underlying the metabolic ecology prediction for tree size distributions. We then develop the alternative demographic equilibrium model, analytically deriving the size distributions it predicts for different combinations of growth and mortality functions and thereby predicting exactly how the parameters of these size distributions are related to parameters of the growth and mortality functions. We test the metabolic ecology prediction using data on tree size distributions in 14 large (16-52 ha) census plots in tropical forests around the globe. We test the demographic equilibrium model in 10 of those forests (those for which we have growth and mortality data) by numerically integrating over the exact observed changes in growth and mortality with size. Finally, we test the utility of the analytical relationships we derive relating growth, mortality and size distributions at demographic equilibrium by fitting each forest's size distribution using each of the functional forms suggested for different combinations of growth and mortality functions, and evaluating how the best-fit parameters of the size distributions compare quantitatively with the values predicted given the best-fit growth and mortality functions.

\section{METABOLIC ECOLOGY THEORY}

West et al. $(1997,1999)$ derive predictions for the scaling of vessel diameters, biomass and metabolic rates of organisms that optimize resource distribution through branching networks of vessels. For plants, their predictions can be stated as follows:

$M 1$ - Prediction: A plant's trunk diameter, $D$ scales with its biomass, $M$ as $M^{3 / 8}$ (thus $M \propto D^{8 / 3}$ ).

M2 - Prediction: A plant's gross photosynthetic rate scales with $M^{3 / 4}$, and thus with $D^{2}$ and with its total leaf area and leaf mass, $L$.

To develop these ideas into predictions for the form of plant size distributions within communities, Enquist \& Niklas (2001) make the following key assumption:

M3 - Assumption: The scaling of the density of plants with plant mass within an old-growth (equilibrium) plant community is the same as the scaling across plant communities varying in mean plant mass. 
They then make use of prior work by Enquist et al. (1998) on plant density variation among communities:

M4 - Assumption: A plant's resource use is proportional to its gross photosynthetic rate.

M5 - Assumption: Plants grow until they are limited by resources.

M6 - Prediction: A plant's resource use scales with $M^{3 / 4}$ (based on M2 and M4).

M7 - Prediction: Across plant communities of similar total resource availability and varying in mean individual plant biomass, plant density, $N$ scales as $M^{-3 / 4}$ (based on M4, M5 and M6).

By combining this last result (M7) with the assumption equating scaling within stands to scaling across stands (M3), Enquist \& Niklas (2001) derive the following prediction:

M8 - Prediction: In old-growth (equilibrium) plant communities, the density of plants of biomass $M$ scales with $M^{-3 / 4}$ and the density of plants of diameter $D$ scales with $D^{-2}$ (based on M1, M3 and M7).

Here, we test how well tree diameter distributions in oldgrowth forests are fit by a power function with exponent -2 (M8). We further evaluate how well these diameter distributions are fit by power functions in general, and whether the best-fit exponents are or are not significantly different from -2 .

\section{DEMOGRAPHIC EQUILIBRIUM THEORY}

An alternative approach to understanding size distributions of old-growth forests starts from the relationship of size distributions with growth and mortality at demographic equilibrium (Kohyama et al. 2003):

D1 - Assumption: In old-growth forests without major long-term temporal variation, stands reach a demographic equilibrium at which mean growth as a function of size, $g(D)$, mortality as a function of size, $m(D)$, and the tree size probability distribution, $p(D)$, are inter-related as

$$
p(D)=\frac{1}{K g(D)} \exp \left[-\int_{D_{0}}^{D} \frac{m(\tilde{D})}{g(\tilde{D})} \mathrm{d} \tilde{D}\right],
$$

where $K$ is a normalization constant (equal to the total number of individuals divided by the recruitment rate) and $D_{0}$ is the size of individuals upon recruitment.

This general relationship has previously been used to numerically calculate what size distributions follow from different growth and mortality functions (e.g. Coomes et al. 2003). Here, we show that this relationship also allows us to analytically derive the tree size distributions that follow from various combinations of growth and mortality scaling functions. We thereby derive the following specific predictions (see Appendix S1 for full derivations):

D2 - Prediction: If absolute diameter growth rates and mortality rates are both constant with diameter and take values $r$ and $a$, respectively (i.e. $g(D)=\mathrm{d} D / \mathrm{d} t=r$ and $m(D)=a)$, the diameter distribution is a negative exponential with rate parameter $\lambda=a / r$.

$p(D)=\frac{1}{K_{e}} \exp \left(-\frac{a}{r} D\right)$,

$p(D)=\frac{1}{K_{e}} \exp (-\lambda D)$,

where $K_{e}$ is a normalization constant whose value depends on $\lambda$ and on $D_{0}$ (see Appendix S1).

D3-Prediction: If growth is a power function of diameter, following

$g(D)=\frac{\mathrm{d} D}{\mathrm{~d} t}=r D^{c}$

and mortality is constant at a $(m(D)=a)$, the diameter distribution will take the form of a Weibull distribution with shape parameter $\mu=1-c$ and scale parameter $v=(r(1-c) / a)^{1 /(1-c)}$

$p(D)=\frac{1}{K_{w}} D^{-c} \exp \left(\frac{-a}{r(1-c)} D^{1-c}\right)$,

$p(D)=\frac{1}{K_{w^{\prime}}}\left(\frac{D}{\beta}\right)^{\mu-1} \exp \left(-\left(\frac{D}{v}\right)^{\mu}\right)$,

where $K_{w}$ and $K_{w^{\prime}}$ are normalization constants.

$D 4$ - Prediction: If growth and mortality are both power functions of diameter, with growth following eqn 3 and mortality following

$m(D)=a D^{b}$

and if the scaling exponents are related such that $c-b=$ 1 (i.e. mortality is proportional to relative growth rate), the diameter distribution will be a power function with exponent $-\theta=-c-a / r=-1-b-a / r$.

$p(D)=\frac{1}{K_{p}} D^{-c-a / r}$

$p(D)=\frac{1}{K_{p}} D^{-1-b-a / r}$,

$p(D)=\frac{1}{K_{p}} D^{-\theta}$,

where $K_{p}$ is a normalization constant. 
Note that metabolic ecology predictions for the scaling exponents of growth $(1 / 3)$ and mortality $(-2 / 3)$ are such that the condition $c-b=1$ is met, and thus, a power function size distribution is predicted - but the exponent will be equal to -2 only if the ratio of the mortality and growth coefficients is such that $a / r=5 / 3$, a condition not specified in previous publications (Enquist et al. 1999; Brown et al. 2004). Note further that when the diameter distribution is a power function, the probability distribution of $\log (D)$ is a truncated exponential distribution with rate parameter $\theta-1$.

D5 - Prediction: If growth and mortality are both power functions of diameter (eqns 3 and 5 ) and $c-b \neq 1$, the diameter distribution will take a form similar to a Weibull distribution with quasi-shape parameter $\alpha=$ $1-c$, quasi-scale parameter $\beta=(r(1-c) / a)^{1 /(1-c)}$, and a third new parameter $\gamma=b$ :

$$
\begin{aligned}
& p(D)=\frac{1}{K_{q}} D^{-c} \exp \left(\frac{-a}{r(1-c+b)} D^{1-c+b}\right), \\
& p(D)=\frac{1}{K_{q}} D^{\alpha-1} \exp \left(-\left(\frac{D}{\beta}\right)^{\alpha+\gamma}\right),
\end{aligned}
$$

where $K_{q}$ is a normalization constant.

Here, we first evaluate whether the assumption that size distributions are in demographic equilibrium (D1) is warranted by numerically integrating eqn 1 over exactly interpolated observed growth and mortality functions and comparing the predicted diameter distributions with those observed. We then fit observed size distributions with exponential, power function, Weibull, and quasi-Weibull functions, examine which function produces the best fit, and compare the fitted parameter values with those expected based on growth and mortality parameters (D2-D5). Because it has been shown that growth and mortality functions change as trees reach the canopy at $c .18$ - to $20-\mathrm{cm}$ diameter (Coomes et al. 2003; Muller-Landau et al. in press), size distributions were fit separately for all individuals combined, for small individuals ( $<20 \mathrm{~cm}$ in diameter) only, and for large individuals $(\geq 20 \mathrm{~cm}$ in diameter) only.

\section{METHODS}

\section{Data sets}

Our study sites are 14 large plots (16-52 ha each) in oldgrowth tropical forests around the world (see Table 1 and Losos \& Leigh 2004). All plots were censused one or more times using the standard methods of the Center for Tropical Forest Science (Condit 1998): all free-standing woody plants with a stem diameter $\geq 1 \mathrm{~cm}$ (at $1.3 \mathrm{~m}$ above the ground) were mapped, tagged, identified to species, and measured in diameter (with a precision of $0.1 \mathrm{~cm}$ - we excluded early censuses in which small stems were measured only to the nearest $0.5 \mathrm{~cm}$ ). We excluded data for individuals whose diameters were recorded as $1.0 \mathrm{~cm}$ to avoid the influence of inconsistencies in the definitions of this smallest size class.

Table 1 The 14 tropical forest dynamics plots used in this study; their sample sizes in area, censuses and trees (with tree number from the

\begin{tabular}{|c|c|c|c|c|c|}
\hline Site & $\begin{array}{l}\text { Plot } \\
\text { area (ha) }\end{array}$ & $\begin{array}{l}\text { No. } \\
\text { censuses }\end{array}$ & $\begin{array}{l}\text { No. } \\
\text { trees }\end{array}$ & $\begin{array}{l}\text { Rainfall } \\
(\mathrm{mm})\end{array}$ & $\begin{array}{l}\text { Dry season } \\
\text { (months) }\end{array}$ \\
\hline Sinharaja Wilderness Area, Sri Lanka & 25 & 2 & 190328 & 5016 & 0 \\
\hline La Planada Nature Reserve, Colombia & 25 & 2 & 99802 & 4415 & 0 \\
\hline Luquillo Experimental Forest, Puerto Rico & 16 & 1 & 64291 & 3548 & 0 \\
\hline Palanan Wilderness Area, Philippines & 16 & 1 & 63891 & 3379 & 0 \\
\hline Yasuni National Park, Ecuador & 25 & 2 & 139566 & 3081 & 0 \\
\hline Lambir Hills National Park, Sarawak, Malaysia & 52 & 2 & 347236 & 2664 & 0 \\
\hline Pasoh Forest Reserve, Malaysia & 50 & 3 & 291954 & 1788 & 1 \\
\hline Korup National Park, Cameroon & 50 & 1 & 314747 & 5272 & 3 \\
\hline Khao Chong Wildlife Refuge, Thailand & 24 & 1 & 96110 & 2660 & 3 \\
\hline Barro Colorado Nature Monument, Panama & 50 & 3 & 209097 & 2551 & 3 \\
\hline Edoro study area, Ituri Forest, Congo & $20^{*}$ & 2 & 149045 & 1785 & 3 \\
\hline Lenda study area, Ituri Forest, Congo & $20^{*}$ & 2 & 127038 & 1674 & 4 \\
\hline Huai Kha Khaeng Wildlife Sanctuary, Thailand & 50 & 2 & 70597 & 1476 & 6 \\
\hline Mudumalai Wildlife Sanctuary, India & 50 & 3 & 18008 & 1250 & 4 \\
\hline
\end{tabular}
most recent census), and their climate

Rainfall is the average annual total; dry season length is the number of calendar months with average rainfall $<100 \mathrm{~mm}$. Climate data from Losos \& Leigh (2004), except for Yasuni (S. J. Wright, personal communication) and Khao Chong (S. J. Davies, unpublished data). Plots are ordered by increasing dryness.

*The two Congo sites each consist of two 10-ha plots; all other sites are one contiguous rectangle or square. 
(At some sites, any stem between 0.95 and $1.05 \mathrm{~cm}$ was recorded as a $1.0-\mathrm{cm}$ stem, while in others only stems between 1.00 and $1.05 \mathrm{~cm}$ were thus recorded.) In total, we analysed over 4.4-million size measurements on over 2.1million individuals in 473 ha.

\section{Evaluating the two models}

To compare the fits of the metabolic ecology (M8) and demographic equilibrium (D1) predictions to the data, we used likelihood, the preferred approach for comparing fits to continuous probability distributions (Johnson et al. 1994). For both models, the predictions were exact, with no fitted parameters. In both cases, we normalized the predicted probability densities so that they summed to exactly one over the total diameter range considered $\left(D_{0}=1.05 \mathrm{~cm}\right.$ to $\left.D_{\max }=499.95 \mathrm{~cm}\right)$. In the case of the theory of metabolic ecology, the prediction can be stated analytically. In a size class $i$ bounded below at $D_{i \min }$ and above at $D_{\text {imax }}$, we should observe a proportion of the total stems equal to

$p_{i, M \text { pred }}=\frac{1 / D_{i \min }-1 / D_{i \max }}{1 / D_{0}-1 / D_{\max }}$.

For the demographic equilibrium theory, numerical methods are necessary. We calculated mean diameter, growth and mortality within wider size classes and then linearly interpolated between these points to obtain complete functions, $g(D)$ and $m(D)$ for growth and mortality (see Appendix S2 and Muller-Landau et al. in press). We then used eqn 1 and numerical integration to obtain the predictions for the number of individuals in each diameter class.

Because measurement precision is limited to $0.1 \mathrm{~cm}$ and thus the data are essentially binned into classes of this width, the likelihood of the complete data set given a predicted probability distribution is essentially a multinomial distribution, $\prod p_{i}^{N_{i}}$ (Kulldorff 1961; Johnson et al. 1994). The total $\log$ likelihood is

$L=\sum_{i} N_{i} \log \left(p_{i}\right)$

We calculate this log likelihood for each model using the finest size classes possible for our data set: classes evenly $0.1-\mathrm{cm}$ wide from 1.05 to $499.95 \mathrm{~cm}$.

\section{Phenomenological fits and their relationships to growth and mortality}

We fitted negative exponential (eqn 2b), Weibull (eqn $4 b$ ), power function (eqn 6c), and quasi-Weibull (eqn 7b) probability distributions to the diameter distributions using maximum likelihood methods (Kulldorff 1961); that is, we searched for the parameters that maximized the log likelihood, as given in eqn 9. We used Akaike's Information Criterion to compare the maximum likelihood fits of the different functions (Burnham \& Anderson 2002). For each census at each plot, we separately fit distributions for all individuals (bins from 1.05 to $500.05 \mathrm{~cm}$ ), small individuals only (measured at $<20 \mathrm{~cm}$ in diameter, thus encompassing bins from 1.05 to $19.95 \mathrm{~cm}$ ), and large individuals only (measured at $\geq 20 \mathrm{~cm}$ in diameter, thus encompassing bins from 19.95 to $500.05 \mathrm{~cm}$ ), always using $0.1-\mathrm{cm}$ bins (the limits of measurement precision). We bootstrapped over $50 \times 50-\mathrm{m}$ subplots to obtain confidence intervals on parameter estimates. The fitted power-function parameters were compared with the -2 value predicted under metabolic ecology, specifically examining whether the confidence intervals included this prediction.

We calculated predicted parameter values of each phenomenological model of tree size distributions from fitted parameters of growth and mortality (eqns 2a, 4a, 6a, $6 \mathrm{~b}$ and $7 \mathrm{a}$ ). The parameters of power functions relating growth and mortality to diameter were obtained from Muller-Landau et al. (in press); details of the fitting methods are given in Appendix S2. We calculated mean growth and mean mortality rates for each site for all individuals, small individuals and large individuals. In each case, we calculated weighted mean values, weighing each size class by its width on a log-diameter scale (size classes were chosen to be approximately equal on a log-diameter scale, while also being bounded at round numbers to avoid the influences of measurement biases). We used weighted mean values because unweighted mean values are dominated by the growth and mortality rates of the very abundant small individuals, which are not typical of all size classes. Confidence intervals on all growth and mortality parameters were obtained by bootstrapping over $50 \times 50$-m subplots. Confidence intervals on the size distribution parameters calculated from the growth and mortality parameters were obtained by bootstrapping over the growth and mortality parameters that went into the calculation (using the confidence intervals of the parameters and assuming errors in the estimates are normally distributed).

To compare predicted and observed size distribution parameters, we first assessed which predicted size distribution model (exponential, power, Weibull or quasi-Weibull) had the highest likelihood of the data across all sites combined. We then used this best model and the most recent census for each site to investigate the degree to which we could explain intersite variation in size distributions in terms of growth and mortality. To do this, we examined the correlations among sites between the size distribution parameters predicted from growth and mortality and the size distribution parameters fitted directly to the tree size data. 


\section{RESULTS}

\section{Evaluating the two models}

In general, tree diameter distributions were qualitatively similar yet quantitatively different across all the closed canopy sites, with a relationship that approximates a power function for small individuals and becomes ever more curvilinear on log-log scales at larger diameters (Fig. 1a-h). The dry, open forest at Mudumalai had a substantially different diameter distribution, with two modes; this site experiences frequent disturbance from fires and elephants (Fig. 1j). The densities of large trees and thus the shape of the size distribution at larger diameters varied widely among the closed canopy sites.
The metabolic ecology prediction of power function size distributions with exponent -2 was a very poor fit for all sites (Fig. 1, Table 2). This is due in large part to large deviations from the power function prediction at large diameters, where there are many fewer individuals than predicted (Table 2). Even at small sizes, however, the metabolic ecology prediction was not a good fit (Table 3), especially at the two more open-canopy forests in the data set, Huai Kha Khaeng and Mudumalai (Fig. 1i,j). The poor fit of the metabolic ecology prediction is further reflected by the phenomenological fits, which show that power functions are never the preferred model for whole-forest distributions, and that their fitted exponents are almost always significantly different from -2 (Table 3 ).
Figure 1 Observed tree size distributions for the most recent censuses of 10 tropical forests (vertical bars) and the predictions of the metabolic ecology (dotted line) and demographic equilibrium (solid line) models. The observed data were grouped into approximately log-even size classes for graphing purposes, and bootstrapping was performed over $50 \times 50-\mathrm{m}$ subplots to obtain 95\% CI (vertical bars) for the densities of trees per 1-cm diameter interval per ha for each of these size classes. (In some cases the confidence intervals are so small that bars appear as dots.) Predicted size distributions are continuous and plotted as such; the likelihood of the data under each prediction was calculated for the full data set using regular $0.1-\mathrm{cm}$ size classes, the limits of measurement precision (see Table 2 for the likelihoods). (a) Sinharaja
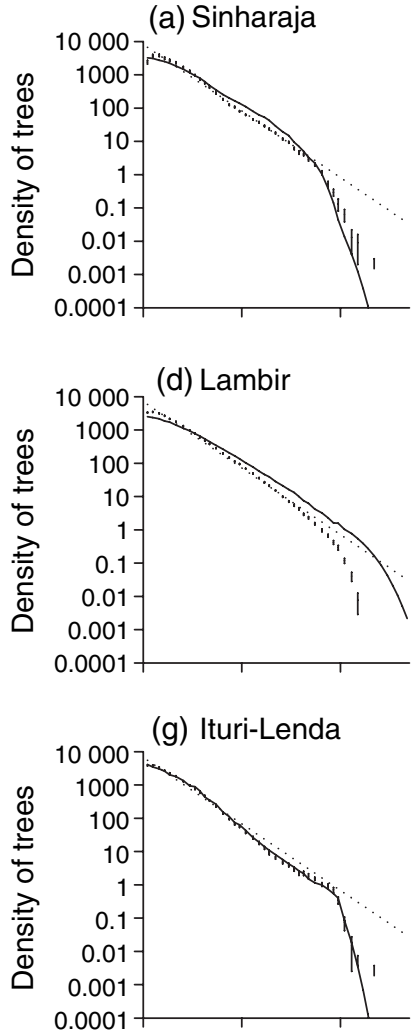

(b) La Planada

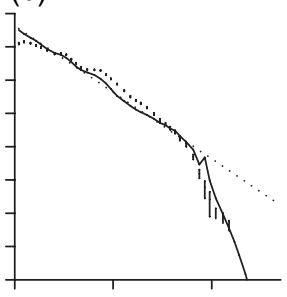

(e) Pasoh

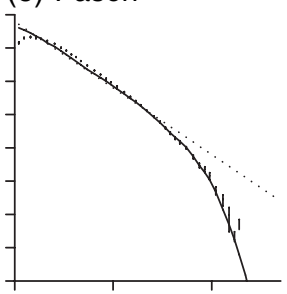

(h) Ituri-Edoro

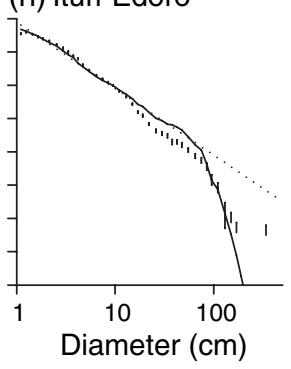

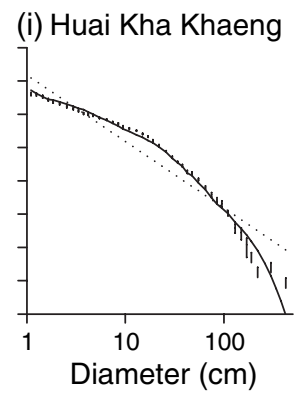

(c) Yasuni

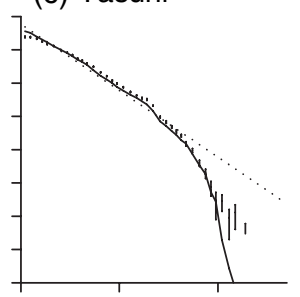

(f) Barro Colorado

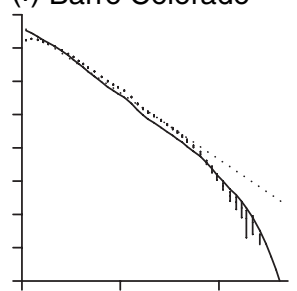

(i) Huai Kha Khaeng

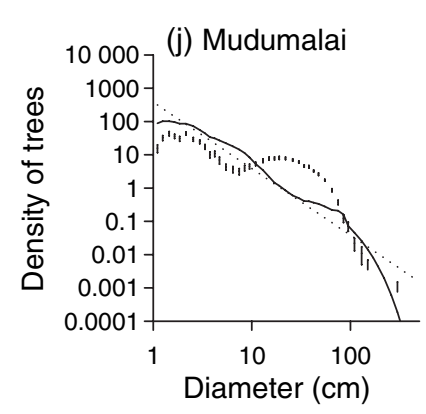




\begin{tabular}{|c|c|c|c|c|}
\hline \multirow[b]{2}{*}{ Site } & \multirow[b]{2}{*}{ Census } & \multicolumn{2}{|c|}{ Log likelihood } & \multirow{2}{*}{$\begin{array}{l}\text { Difference } \\
\text { in log likelihoods } \\
(\mathrm{ME}-\mathrm{DE})\end{array}$} \\
\hline & & $\begin{array}{l}\text { Metabolic } \\
\text { ecology }\end{array}$ & $\begin{array}{l}\text { Demographic } \\
\text { equilibrium }\end{array}$ & \\
\hline Sinharaja & 1995 & -833722 & -838183 & 4461 \\
\hline Sinharaja & 2000 & -827307 & -824867 & -2441 \\
\hline La Planada & 1997 & -539709 & -534125 & -5584 \\
\hline La Planada & 2003 & -494607 & -489056 & -5551 \\
\hline Yasuni & 1997 & -680775 & -673615 & -7160 \\
\hline Yasuni & 2004 & -651039 & -643494 & -7545 \\
\hline Lambir & 1992 & -1479775 & -1 491397 & 11622 \\
\hline Lambir & 1997 & -1527610 & -1540531 & 12921 \\
\hline Pasoh & 1990 & -1404963 & -1392765 & -12198 \\
\hline Pasoh & 1995 & -1404615 & -1390759 & -13857 \\
\hline Pasoh & 2000 & -1341067 & -1326366 & -14700 \\
\hline Barro Colorado & 1990 & -1034347 & -1032609 & -1738 \\
\hline Barro Colorado & 1995 & -984831 & -983861 & -970 \\
\hline Barro Colorado & 2000 & -943374 & -942460 & -914 \\
\hline Ituri-Edoro & 1995 & -643365 & -639077 & -4288 \\
\hline Ituri-Edoro & 2000 & -634505 & -629716 & -4789 \\
\hline Ituri-Lenda & 1995 & -523558 & -520162 & -3396 \\
\hline Ituri-Lenda & 2000 & -522669 & -518851 & -3818 \\
\hline Huai Kha Khaeng & 1993 & -418929 & -400087 & -18842 \\
\hline Huai Kha Khaeng & 1999 & -401398 & -380264 & -21134 \\
\hline Mudumalai & 1992 & -138494 & -133008 & -5487 \\
\hline Mudumalai & 1996 & -126383 & -121525 & -4858 \\
\hline Mudumalai & 2000 & -135178 & -130692 & -4486 \\
\hline
\end{tabular}

Table 2 The fit of the metabolic ecology and demographic equilibrium models to the diameter distribution data for each census of each site, as reflected in the total log likelihood of the data

Note that there are no free parameters for either model, and thus the Akaike Information Criterion is equal simply to -2 times the log likelihood. The better score for each site and census combination is highlighted in boldface, and the difference between the two is given in a separate column where positive values indicate a better fit for the metabolic ecology model (higher log likelihoods) and negative values a better fit for the demographic equilibrium model. To put these numbers in perspective, note that a difference in log likelihoods of just 9 indicates that the likelihood of the data under the better model is 10000 times greater than under the worse model. Sites are ordered by increasing dryness.

The demographic equilibrium prediction, in contrast, was able to capture the fundamental curvature of the size distributions, and thus was generally a better fit to the data. A notable exception was Lambir, where the demographic equilibrium model predicted many more large individuals than were observed (Fig. 1d). The likelihood of the data was much higher under the demographic equilibrium model than under the metabolic ecology model in 20 of 23 data sets; the exceptions were the two censuses at Lambir and the first census at Sinharaja (Table 2).

\section{Phenomenological fits and their relationships to growth and mortality}

Of the four phenomenological models that were fitted (eqns 2b, 4b, 6c and 7b), the three-parameter quasi-Weibull distribution proved the best fit for 24 of 27 whole-forest (all-individual) data sets, with the Weibull just barely superior to it in the other three cases (Table 3). These two functions were always the top two in their Akaike Information Criteria; the power and exponential functions were far behind (Table S1). When size distributions of small individuals or large individuals alone were fit, the quasi-Weibull was again the best fit in 48 of 54 cases (Table 3). The power function did better than the exponential among small individuals, and the exponential better than the power function among large individuals, but both were almost always far inferior in their fit to the Weibull and quasi-Weibull (Table S1). The power function was the best fit for only two of 81 data sets: small individuals at Luquillo and in the first census at Huai Kha Khaeng. The exponential function was the best fit for only one of 81 data sets: large individuals at Luquillo.

The shapes of these diameter distributions differed significantly from the power-function prediction of 
Table 3 Comparison of the maximum likelihood fits to the size distributions of all individuals, small individuals $(<20$-cm diameter), and large individuals $(\geq 20$-cm diameter) for all sites and censuses

\begin{tabular}{|c|c|c|c|c|c|c|c|}
\hline \multirow[b]{2}{*}{ Site } & \multirow[b]{2}{*}{ Census } & \multicolumn{3}{|c|}{ Best-fit function } & \multicolumn{3}{|c|}{ Power-function exponent, theta (eqn 6c) $(95 \% \mathrm{CI})$} \\
\hline & & All & Small & Large & All & Small & Large \\
\hline Sinharaja & 1995 & W & $\mathrm{Q}^{* * * *}$ & $\mathrm{Q}^{* * * *}$ & $2.05(2.02-2.07)$ & $1.96(1.93-2.00)$ & $3.01(2.93-3.09)$ \\
\hline Sinharaja & 2000 & $\mathrm{Q}^{* * * *}$ & $\mathrm{Q}^{* * * *}$ & $\mathrm{Q}^{* * * *}$ & $1.99(1.96-2.01)$ & $1.86(1.82-1.90)$ & $3.01(2.94-3.07)$ \\
\hline La Planada & 1997 & Q & $\mathrm{Q}^{* * * *}$ & $\mathrm{Q}^{* * * *}$ & $1.78(1.77-1.79)$ & $1.48(1.46-1.50)$ & $3.39(3.33-3.46)$ \\
\hline La Planada & 2003 & $\mathrm{Q}^{* *}$ & $\mathrm{Q}^{* * * *}$ & $\mathrm{Q}^{* *}$ & $1.73(1.72-1.74)$ & $1.40(1.38-1.41)$ & $3.39(3.33-3.46)$ \\
\hline Luquillo & 1992 & $\mathrm{Q}^{* * * *}$ & $\mathrm{P} * * * *$ & $\mathrm{E}$ & $1.75(1.73-1.78)$ & $1.46(1.41-1.50)$ & $3.16(3.07-3.25)$ \\
\hline Palanan & 1998 & $\mathrm{Q}^{* * * *}$ & $\mathrm{Q}^{* * * *}$ & $\mathrm{Q}^{* * * *}$ & $1.81(1.80-1.83)$ & $1.61(1.58-1.64)$ & $2.95(2.87-3.04)$ \\
\hline Yasuni & 1997 & $\mathrm{Q}^{* * * *}$ & $\mathrm{Q}^{* * * *}$ & $\mathrm{Q}^{*}$ & $1.86(1.85-1.87)$ & $1.62(1.60-1.64)$ & $3.68(3.60-3.77)$ \\
\hline Yasuni & 2004 & $\mathrm{~W}$ & $\mathrm{Q}^{* * * *}$ & $\mathrm{~W}$ & $1.84(1.83-1.85)$ & $1.59(1.57-1.60)$ & $3.65(3.57-3.72)$ \\
\hline Lambir & 1992 & $\mathrm{Q}^{* * * *}$ & $\mathrm{Q}^{* * * *}$ & $\mathrm{Q}^{* * * *}$ & $1.95(1.95-1.96)$ & $1.80(1.79-1.81)$ & $2.91(2.88-2.94)$ \\
\hline Lambir & 1997 & $\mathrm{~W}$ & $\mathrm{Q}^{* * * *}$ & $\mathrm{Q}^{* * * *}$ & $1.96(1.95-1.97)$ & $1.81(1.80-1.82)$ & $2.91(2.87-2.94)$ \\
\hline Pasoh & 1990 & $\mathrm{Q}^{* * * *}$ & $\mathrm{Q}^{* * * *}$ & $\mathrm{Q}^{* * * *}$ & $1.93(1.93-1.94)$ & $1.73(1.71-1.74)$ & $3.15(3.11-3.19)$ \\
\hline Pasoh & 1995 & $\mathrm{Q}^{* * * *}$ & $\mathrm{Q}^{* * * *}$ & $\mathrm{Q}^{* * * *}$ & $1.90(1.89-1.91)$ & $1.66(1.65-1.68)$ & $3.19(3.15-3.23)$ \\
\hline Pasoh & 2000 & $\mathrm{Q}^{* * * *}$ & $\mathrm{Q}^{* * * *}$ & $\mathrm{Q}^{* * * *}$ & $1.87(1.86-1.88)$ & $1.61(1.60-1.63)$ & $3.18(3.14-3.22)$ \\
\hline Korup & 1998 & $\mathrm{Q}^{* * * *}$ & $\mathrm{Q}^{* * * *}$ & $\mathrm{Q}^{*}$ & $1.96(1.95-1.97)$ & $1.79(1.78-1.81)$ & $3.28(3.23-3.32)$ \\
\hline Khao Chong & 2001 & $\mathrm{Q}^{* * * *}$ & $\mathrm{Q}^{* * *}$ & $\mathrm{Q}$ & $1.84(1.82-1.86)$ & $1.61(1.59-1.64)$ & $3.04(2.97-3.11)$ \\
\hline Barro Colorado & 1990 & $\mathrm{Q}^{* * * *}$ & $\mathrm{Q}^{* * * *}$ & Q & $1.97(1.96-1.97)$ & $1.81(1.80-1.82)$ & $2.83(2.78-2.87)$ \\
\hline Barro Colorado & 1995 & $\mathrm{Q}^{* * * *}$ & $\mathrm{Q}^{* * * *}$ & W & $1.93(1.93-1.94)$ & $1.76(1.75-1.77)$ & $2.85(2.81-2.90)$ \\
\hline Barro Colorado & 2000 & $\mathrm{Q}^{* * * *}$ & $\mathrm{Q}^{* * * *}$ & Q & $1.90(1.90-1.91)$ & $1.72(1.71-1.73)$ & $2.84(2.79-2.88)$ \\
\hline Ituri-Edoro & 1995 & $\mathrm{Q}^{* * * *}$ & $\mathrm{Q}^{* * * *}$ & $\mathrm{Q}^{* * * *}$ & $2.07(2.05-2.08)$ & $1.90(1.88-1.92)$ & $2.56(2.50-2.63)$ \\
\hline Ituri-Edoro & 2000 & $\mathrm{Q}^{* * * *}$ & $\mathrm{Q}^{* * * *}$ & Q & $2.04(2.02-2.05)$ & $1.86(1.84-1.88)$ & $2.60(2.54-2.66)$ \\
\hline Ituri-Lenda & 1995 & $\mathrm{Q}^{* * * *}$ & $\mathrm{Q}^{* * * *}$ & $\mathrm{Q}^{* * * *}$ & $2.13(2.12-2.15)$ & $2.05(2.04-2.07)$ & $2.43(2.38-2.48)$ \\
\hline Ituri-Lenda & 2000 & $\mathrm{Q}^{* * * *}$ & $\mathrm{Q}^{* * * *}$ & $\mathrm{Q}^{* * * *}$ & $2.13(2.11-2.14)$ & $2.04(2.02-2.06)$ & $2.42(2.36-2.47)$ \\
\hline Huai Kha Khaeng & 1993 & $\mathrm{Q}^{* * * *}$ & $\mathrm{P} * *$ & $\mathrm{Q}^{* * *}$ & $1.56(1.54-1.58)$ & $1.17(1.13-1.21)$ & $2.93(2.89-2.97)$ \\
\hline Huai Kha Khaeng & 1999 & $\mathrm{Q}^{* * * *}$ & $\mathrm{~W}$ & $\mathrm{Q}^{* * *}$ & $1.52(1.50-1.54)$ & $1.08(1.04-1.12)$ & $2.95(2.91-2.99)$ \\
\hline Mudumalai & 1992 & $\mathrm{Q}^{* * * *}$ & $\mathrm{Q}^{* * *}$ & $\mathrm{Q}^{* * * *}$ & $1.08(1.06-1.10)$ & $-0.06(-0.22$ to 0.10$)$ & $2.86(2.80-2.92)$ \\
\hline Mudumalai & 1996 & $\mathrm{Q}^{* * * *}$ & $\mathrm{Q}^{* * * *}$ & $\mathrm{Q}^{* * * *}$ & $1.04(1.02-1.05)$ & $-0.23(-0.41$ to -0.07$)$ & $2.81(2.75-2.88)$ \\
\hline Mudumalai & 2000 & $\mathrm{Q}^{* * * *}$ & $\mathrm{Q}^{* * * *}$ & $\mathrm{Q}^{* * * *}$ & $1.16(1.14-1.18)$ & $0.75(0.67-0.83)$ & $2.75(2.70-2.81)$ \\
\hline
\end{tabular}

The best-fit function is the one with the lowest Akaike Information Criterion (AIC): Weibull (W), power function (P), exponential (E) or quasi-Weibull $(\mathrm{Q})$ distribution. Asterisks indicate whether the three inferior models have combined Akaike weights of $<0.05(*), 0.01(* *)$, $0.001(* * *)$ or $0.0001\left(^{* * * *}\right)$ (Burnham \& Anderson 2002). For every data set, the best-fit power function exponent with its $95 \%$ confidence interval is listed. Confidence intervals were obtained from 1000 bootstraps over $50 \times 50$-m subplots. Plots are ordered by increasing dryness. The AIC values for all fits are given in Table S1.

metabolic ecology. Moreover, the best-fit power-function exponents for the whole size distribution were significantly different from the predicted slope of -2 in 13 of 14 forests (Table 3). When diameter distributions of small individuals alone were fitted, the exponents were significantly greater than -2 (shallower slopes) at 13 of 14 sites and significantly smaller at the remaining site; for large individuals, they were significantly smaller than -2 (steeper slopes) for all sites. In all cases, the exponents for small and large individuals were highly significantly different, reflecting the strong changes in shape of the size distribution with tree size.

Among the five size probability distributions predicted from growth and mortality (eqn 2a, 4a, 6a, 6b and 7a), the Weibull proved to be the most reliable predictor, as exemplified by having the highest likelihood of the data
(Table S2). When examining only data sets for the full diameter distribution (all individuals), the quasi-Weibull and Weibull were each best at four sites, while the power function was best at Lambir and the exponential was best at Mudumalai. When the quasi-Weibull was not the best, it was always much worse than the best fit; in contrast, when the Weibull was not the very best, it generally was the closest second best. The Weibull also was by far the best predictor among the data sets for only small and large individuals (Table S2).

The match to the diameter distributions of the fitted and predicted models is demonstrated graphically in Fig. 2 for one census at one site, and in Fig. S1 for all other censuses and sites. The site shown, Barro Colorado (data available on the web at: http://ctfs.si.edu/datasets/bci/), is typical in the much better fit obtained by the fitted Weibull and 
(a)

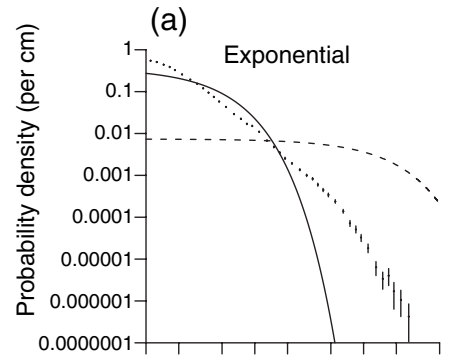

(b)

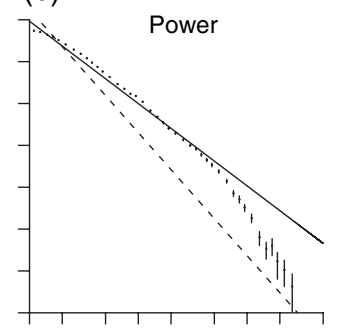

(c)

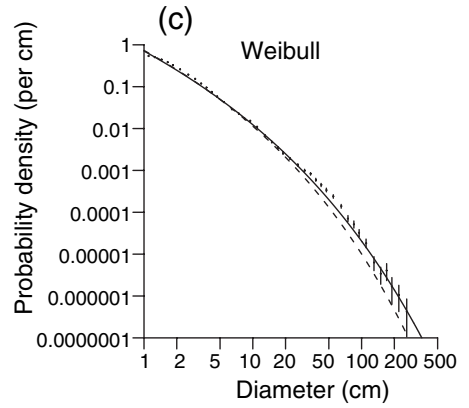

(d)

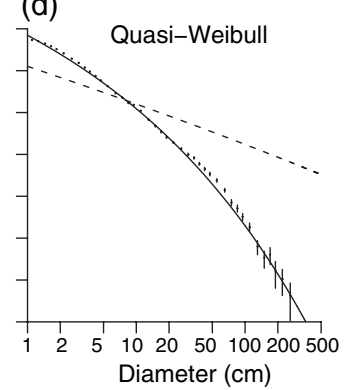

Figure 2 The observed tree size distribution from the 1990 census on Barro Colorado (vertical bars), maximum likelihood fits of various phenomenological models to the size distribution (solid lines), and the corresponding functions predicted by the demographic equilibrium model based on the change in growth and mortality with size (dashed lines). (a) Exponential distribution model, with fits to eqn $2 \mathrm{~b}$ and predictions based on eqn 2a; (b) power function model, with fits to eqn $6 \mathrm{c}$ and predictions based on eqn 6b; (c) Weibull distribution model, with fits to eqn $4 \mathrm{~b}$ and predictions based on eqn $4 \mathrm{a}$; (d) quasiWeibull distribution model, with fits to eqn $7 \mathrm{~b}$ and predictions based on eqn 7a. Again, for graphing purposes only the observed data were grouped into approximately log-even size classes, with $95 \%$ CI based on bootstrapping over $50 \times 50-\mathrm{m}$ subplots. Fits were carried out to the full data set using regular $0.1-\mathrm{cm}$ size classes (the limits of measurement precision). Fitted parameter values and their bootstrapped CIs are given in Table 3 and Table S1.

quasi-Weibull over the fitted power and exponential distributions. It is also typical in the good match of the predicted Weibull distribution, and in the poor matches for the predicted exponential and power functions. The fit of the predicted quasi-Weibull distribution is highly variable among sites, and is sometimes much better than at Barro Colorado (Table S2).

Variation among sites in the parameters of the best-fit Weibull to the tree diameter distribution was in part explained by growth and mortality. The Weibull parameters predicted based on growth and mortality (eqn 4) were positively correlated with the fitted parameters, with model 2 regression slopes not significantly different from $1: 1$ (Fig. 3). The shape parameters were significantly correlated
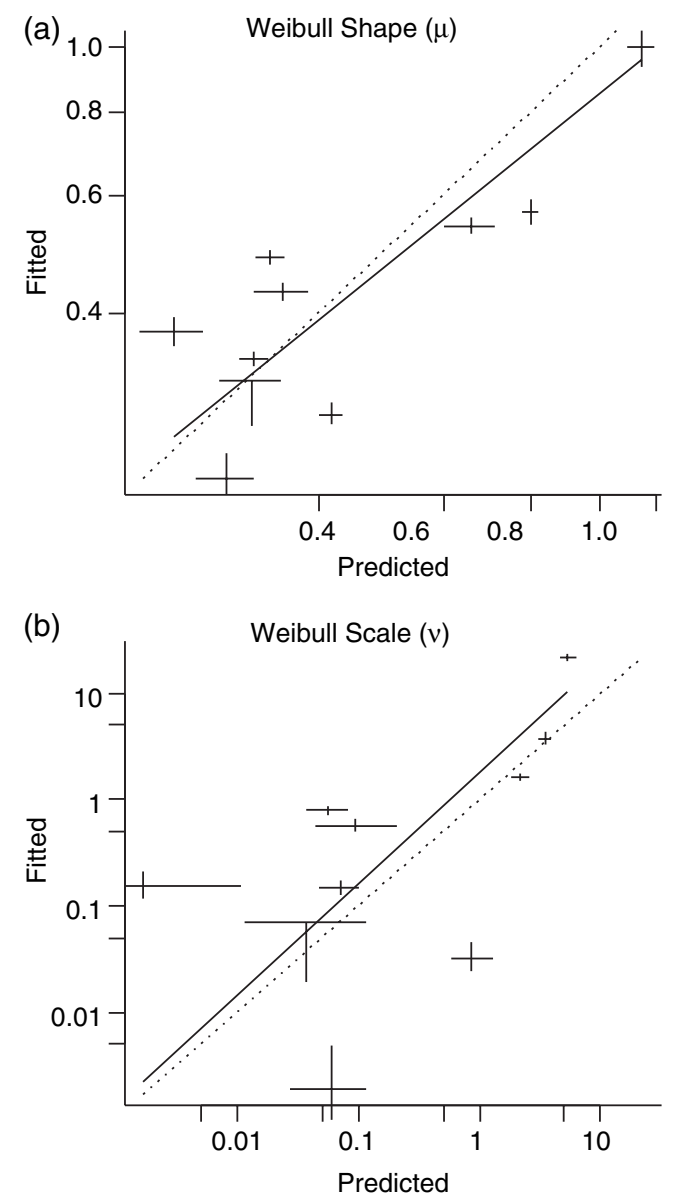

Figure 3 The relationship between the predicted (from growth and mortality) and best-fit (using maximum likelihood) Weibull parameters of the tree diameter distribution across sites. There is one point per site, with only the most recent census represented. Confidence intervals on predicted and fitted parameters are based on bootstrapping over $50 \times 50$-m subplots. The solid line shows the model 2 regression of the log-transformed parameters; the dotted line is $1: 1$.

( $n=10, r^{2}=0.68, P=0.003$ ), while the scale parameters were marginally so $\left(n=10, r^{2}=0.30, P=0.10\right)$.

\section{DISCUSSION}

\section{Assessing existing models for tree size distributions}

The metabolic ecology prediction for the scaling of tree abundance with diameter in old-growth forests was unequivocally rejected in all 14 tropical forests examined here. We believe the core problem is the assumption that the same logic that determines the densities of plants in thinning even-aged stands applies to the relative abundances of size classes in mixed-aged stands. While different stands of even age and size have access to the same total resources, the 
same is not true of different size classes of trees within mixed-aged forests. Further, the number of individuals in each size class is not necessarily limited strictly by the energy that reaches that size class, as reflected in competitioninduced mortality that thins abundant recruits to a fixed number that use all available energy. Instead, the number of individuals may be limited to a lower level based on the rate at which individuals are removed by mortality unrelated to resource competition, and the rates at which they grow into and out of the size class.

The demographic equilibrium model is based on exactly these considerations of the joint influences of growth and mortality in determining the change in number of individuals with size, and thus it provides both an accurate and useful explanation of the form of tree size distributions in old-growth tropical forests. Under this model, a powerfunction size distribution emerges as a special case when growth and mortality are themselves both power functions of size, with mortality proportional to the relative growth rate. One way in which this last condition can be met is if both relative growth and mortality are proportional to the mass-specific gross photosynthetic rate, as hypothesized by both metabolic ecology theory (Brown et al. 2004) and an alternative incorporating change in resource availability with size (Muller-Landau et al. in press). Thus, the approximately power-function size distribution among 'small' individuals informs us of the approximate proportionality of relative growth and mortality in these size classes, consistent with the results of Muller-Landau et al. (in press). Such proportionality may in turn reflect the dominant influence of resource availability and competition in determining both growth and mortality below the canopy (Coomes et al. 2003). Similarly, the lack of a power-function relationship among large individuals can be interpreted as demonstrating the partial decoupling of growth and mortality in these size classes. As hypothesized by Coomes et al. (2003), this may be because mortality is at least partly independent of resource availability and competition among large trees. Differences in growth and mortality scaling between small and large individuals may also in part reflect differences in species composition and thus in life-history strategies and allocation patterns.

The linkage between size distributions, growth and mortality in forests at equilibrium is potentially a useful tool both for estimating one quantity from the other two and for detecting departures from equilibrium. However, despite the fact that predicted and fitted size distribution parameters were positively correlated with slopes not significantly different from one across sites (Fig. 3), these relationships were not sufficiently tight to permit reliable predictions of size distributions from growth and mortality (note the mostly non-overlapping confidence intervals in Table S3). We believe this reflects strong interannual variation in growth and mortality, which means that longer-term data sets are necessary to accurately estimate the long-term average growth and mortality rates that should determine equilibrium size distributions. This temporal variation in growth and mortality also leads to temporal variation in tree size distributions, and thus in itself represents a deviation from homogenous equilibrium assumptions and predictions. Thus, comparisons of predicted and observed size distributions are a very crude tool to detect departures from equilibrium, able only to detect particularly large deviations such as those observed at Lambir. In practice, departures from equilibrium can be better detected by comparing forest structure among the two or more censuses required to calculate growth and mortality.

The failure of the demographic equilibrium model, both in its exact (eqn 1) and approximate (eqns 2a, 4a, 6a, 6b and 7a) forms at Lambir is consistent with other data indicating that this forest was far from steady state. Total above-ground biomass increased dramatically between the 1992 and 1997 censuses. This may reflect recovery from previous large-scale tree mortality. Interannual variation in growth and mortality in Southeast Asia is closely tied to the El Niño Southern Oscillation cycle, with droughts and thus high tree mortality during El Niño events (Salafsky 1998; Potts 2003; van Nieuwstadt \& Sheil 2005). The 1992-1997 census interval is notable in not containing an El Niño event, and thus, we might expect a net accrual of tree biomass during such a time period. Further, the lack of an El Niño event during the measurement period implies that our estimates of mortality (and growth) rates at Lambir probably underestimate (and overestimate) long-term average rates, and thus overestimate the long-term equilibrium densities of large trees.

\section{Significance and future directions}

The results presented here add to a growing body of evidence demonstrating that there is no site- and sizeindependent scaling relationship of tree abundance with diameter among trees in old-growth forests, tropical or temperate (Coomes et al. 2003). Instead, there are significant quantitative differences in tree size distributions among forests, differences that our work suggests are related proximally to among-site variation in tree growth and mortality. Among-site variation in the scaling of growth and mortality with size in turn reflects variation in tree allometries and the scaling of resource availability with size (Muller-Landau et al. in press). The most important resource for determining changes in resource availability with size is almost certainly light, because light is clearly limiting and competition for light is highly size asymmetric. Variation in the scaling of light availability within forests itself depends 
on the tree size distribution and especially the abundances of large trees (Nicotra et al. 1999; Montgomery \& Chazdon 2001; Montgomery 2004). Thus, ultimately, variation in tree size distributions and resource availability is interlinked and feeds back upon itself, and a complete explanation requires an understanding of these linkages.

Despite the observed variability, there is considerable consistency in the scaling of size distributions within and among closed canopy forests - indeed, more than would be expected based on growth and mortality alone. This is especially evident for subcanopy individuals and within sites, where the growth and mortality patterns (Muller-Landau et al. in press) are more variable among censuses than the size distributions. This consistency indicates the presence of negative feedbacks, such that a decrease in the abundance of trees results in increased growth and decreased mortality until the forest returns to its previous size distribution. Models that explicitly incorporate resource dynamics can capture these types of feedbacks (Pacala et al. 1996; Chave 1999), and such models provide the best avenue for understanding the ultimate causes of the similarities and differences among forests observed here.

Muller-Landau et al. (in press) hypothesize that the key factor for understanding differences and similarities in growth and mortality functions among forests is the relative degree to which large individuals can monopolize resources vs. the degree to which their abundance and resource monopolization are limited by other factors such as lethal disturbances (Coomes et al. 2003) or relatively more symmetric resource competition (Stoll et al. 2002). We propose that this same factor is critical for tree size distributions as well. Among-site variation in size distributions is, by definition, greatest between what we refer to as closed and open canopy forests. In open canopy forests, the abundance of large trees is obviously far below its theoretical maximum - in the two forests here because of recurring fire and elephants (Sukumar et al. 2005). Even in closed canopy forests, the densities of large trees are limited by the mortality imposed by droughts, wind storms, lightning and disease. In some cases, mortality rates of large trees may be fairly similar across years, reflecting the dominance of frequent small-scale events; in other cases, strong interannual variation may reflect the importance of rare and typically large-scale events (Asner et al. 2000; Williamson et al. 2000). It will take much longer-term records than we have to date to disentangle the relative influences of different processes in determining large tree mortality rates.

If we are correct, then attempts to understand geographical variation in the above-ground biomass of tropical forests today and to predict future changes to associated carbon stores should focus on the determinants of mortality rates of large trees (Loehle 1988, 2000). The gaps made in the canopy by the deaths of large trees due to disturbances or droughts may quickly be filled by smaller trees, but the gaps in the size class are not. Anthropogenic global change may be increasing the frequency and severity of cyclones and hurricanes (Webster et al. 2005), which can cause great increases in tropical tree mortality (Zimmerman et al. 1994). These changes may lead to permanently lower long-term average abundances of large trees in many tropical forests, and concomitant decreases in above-ground carbon stores. A better, more mechanistic understanding of tropical forest structure and dynamics will provide insight into both geographical variation today and future forest change.

\section{ACKNOWLEDGEMENTS}

We thank Joe Wright, Steve Pacala, Jerome Chave, Bert Leigh, David Coomes, Robin Chazdon, and two anonymous referees for comments on the manuscript, Deborah Clark and Gary Mittelbach for useful suggestions, and Sandy Weisberg of the University of Minnesota School of Statistics for statistical advice. We gratefully acknowledge the contributions of the many dedicated people and generous funders that have made possible the forest dynamics plot data sets upon which this research is based. We especially thank the US National Science Foundation for funding the workshop at which this study was initiated (DEB-9806828). HCM thanks the University of Minnesota and the National Center for Ecological Analysis and Synthesis, a centre funded by NSF and the state of California, for support. This material was developed while JKZ was serving at the National Science Foundation. Any opinions, findings, conclusions or recommendations expressed in this material are those of the authors and do not necessarily reflect the views of the National Science Foundation.

\section{REFERENCES}

Ashton, P.S. \& Hall, P. (1992). Comparisons of structure among mixed dipterocarp forests of north-western Borneo. J. Ecol., 80, 459-481.

Asner, G.P., Townsend, A.R. \& Braswell, B.H. (2000). Satellite observation of El Niño effects on Amazon forest phenology and productivity. Geophys. Res. Lett., 27, 981-984.

Bailey, R.L. \& Dell, T.R. (1973). Quantifying diameter distributions with Weibull function. For. Sci., 19, 97-104.

Baker, T.R., Phillips, O.L., Malhi, Y., Almeida, S., Arroyo, L., Di Fiore, A. et al. (2004). Increasing biomass in Amazonian forest plots. Philos. Trans. R. Soc. Lond. Ser. B, Biol. Sci., 359, 353 365.

Brown, J.H., Gillooly, J.F., Allen, A.P., Savage, V.M. \& West, G.B. (2004). Toward a metabolic theory of ecology. Ecology, 85, 17711789.

Burnham, K.P. \& Anderson, D.R. (2002). Model Selection and Inference: A Practical Information-theoretic Approach, 2nd edn. Springer, New York, NY. 
Chave, J. (1999). Study of structural, successional and spatial patterns in tropical rain forests using TROLL, a spatially explicit forest model. Ecol. Modell., 124, 233-254.

Chave, J., Riera, B. \& Dubois, M.A. (2001). Estimation of biomass in a neotropical forest of French Guiana: spatial and temporal variability. J. Trop. Ecol., 17, 79-96.

Condit, R. (1998). Tropical Forest Census Plots. Springer-Verlag, Berlin and R. G. Landes Company, Georgetown, TX, USA.

Condit, R., Sukumar, R., Hubbell, S.P. \& Foster, R.B. (1998). Predicting population trends from size distributions: a direct test in a tropical tree community. Am. Nat., 152, 495-509.

Coomes, D.A., Duncan, R.P., Allen, R.B. \& Truscott, J. (2003). Disturbances prevent stem size-density distributions in natural forests from following scaling relationships. Ecol. Lett., 6, 980989.

DeLiocourt, F. (1898). De l'amenágement des sapinières. Soc. For. Franche-comté Belfort Bull., 6, 369-405.

Dixon, R.K., Brown, S., Houghton, R.A., Solomon, A.M., Trexler, M.C. \& Wisniewski, J. (1994). Carbon pools and flux of global forest ecosystems. Science, 263, 185-190.

Ebert, T.A., Schroeter, S.C. \& Dixon, J.D. (1993). Inferring demographic-processes from size-frequency distributions - effect of pulsed recruitment on simple-models. Fish. Bull., 91, 237-243.

Enquist, B.J. \& Niklas, K.J. (2001). Invariant scaling relations across plant communities. Nature, 410, 655-660.

Enquist, B.J., Brown, J.H. \& West, G.B. (1998). Allometric scaling of plant energetics and population density. Nature, 395, 163-165.

Enquist, B.J., West, G.B., Charnov, E.L. \& Brown, J.H. (1999). Allometric scaling of production and life-history variation in vascular plants. Nature, 401, 907-911.

Goff, F.G. \& West, D. (1975). Canopy-understory interaction effects on forest population structure. For. Sci., 21, 98-107.

Goodburn, J.M. \& Lorimer, C.G. (1999). Population structure in old-growth and managed northern hardwoods: an examination of the balanced diameter distribution concept. For. Ecol. Manage, 118, 11-29.

Johnson, N.L., Kotz, S. \& Balakrishnan, N. (1994). Continuous Univariate Distributions, 2nd edn. John Wiley \& Sons, New York, NY.

Kohyama, T. (1991). Simulating stationary size distribution of trees in rain forests. Ann. Bot., 68, 173-180.

Kohyama, T., Suzuki, M., Partomihardjo, T., Yamada, T. \& Kubo, T. (2003). Tree species differentiation in growth, recruitment and allometry in relation to maximum height in a Bornean mixed dipterocarp forest. J. Ecol., 91, 797-806.

Kulldorff, G. (1961). Contributions to the Theory of Estimation from Grouped and Partially Grouped Samples. Wiley, New York, NY.

Leak, W.B. (1964). An expression of diameter distribution for unbalanced, uneven-aged stands and forests. For. Sci., 10, 39-50.

Loehle, C. (1988). Tree life history strategies: the role of defenses. Can. J. For. Res., 18, 209-222.

Loehle, C. (2000). Strategy space and the disturbance spectrum: a life-history model for tree species coexistence. Am. Nat., 156, 14-33.

Lorimer, C.G. \& Frelich, L.E. (1984). A simulation of equilibrium diameter distributions of sugar maple (Acer saccharum). Bull. Torrey Bot. Club, 111, 193-199.

Losos, E.C. \& Leigh, E.G. (2004). Forest Diversity and Dynamism: Findings from a Network of Large-scale Tropical Forest Plots. University of Chicago Press, Chicago, IL.
Meyer, H.A. \& Stevenson, D.D. (1943). The structure and growth of virgin beech-birch-hemlock forests in northern Pennsylvania. J. Agric. Res., 67, 465-484.

Montgomery, R.A. (2004). Effects of understory foliage on patterns of light attenuation near the forest floor. Biotropica, 36, 33-39.

Montgomery, R.A. \& Chazdon, R.L. (2001). Forest structure, canopy architecture, and light transmittance in tropical wet forests. Ecology, 82, 2707-2718.

Moser, J.W. (1972). Dynamics of an uneven-aged forest stand. For. Sci., 18, 184-191.

Muller-Landau, H.C., Condit, R.S., Chave, J., Thomas, S.C., Bohlman, S.A., Bunyavejchewin, S. et al. (2006). Testing metabolic ecology theory for allometric scaling of tree size, growth, and mortality in tropical forests. Ecol. Lett. doi: 10.1111/j.14610248.2006.00905.x

Nicotra, A.B., Chazdon, R.L. \& Iriarte, S.V.B. (1999). Spatial heterogeneity of light and woody seedling regeneration in tropical wet forests. Ecology, 80, 1908-1926.

van Nieuwstadt, M.G.L. \& Sheil, D. (2005). Drought, fire and tree survival in a Borneo rain forest, East Kalimantan, Indonesia. J. Ecol., 93, 191-201.

Niklas, K.J., Midgley, J.J. \& Rand, R.H. (2003). Tree size frequency distributions, plant density, age and community disturbance. Ecol. Lett., 6, 405-411.

Pacala, S.W., Canham, C.D., Saponara, J., Silander, J.A.J., Kobe, R.K. \& Ribbens, E. (1996). Forest models defined by field measurements: estimation, error analysis and dynamics. Ecol. Monogr., 66, 1-43.

Potts, M.D. (2003). Drought in a Bornean everwet rain forest. J. Ecol., 91, 467-474.

Salafsky, N. (1998). Drought in the rain forest, part II - an update based on the 1994 ENSO event. Clim. Change, 39, 601-603.

Schwartz, J.W., Nagel, L.M. \& Webster, C.R. (2005). Effects of uneven-aged management on diameter distribution and species composition of northern hardwoods in Upper Michigan. For. Ecol. Manage, 211, 356-370.

Sinko, J.W. \& Streifer, W. (1967). A new model for age-size structure of a population. Ecology, 48, 910-918.

Smith, B.D., Botsford, L.W. \& Wing, S.R. (1998). Estimation of growth and mortality parameters from size frequency distributions lacking age patterns: the red sea urchin (Strongylocentrotus franciscanus) as an example. Can. J. Fish. Aquat. Sci., 55, 1236-1247.

Stoll, P., Weiner, J., Muller-Landau, H., Müller, E. \& Hara, T. (2002). Size symmetry of competition alters biomass-density relations. Proc. R. Soc. Biol. Sci. Ser. B, 269, 2191-2195.

Sukumar, R., Suresh, H.S., Dattaraja, H.S., Srinidhi, S. \& Nath, C. (2005). The dynamics of a tropical dry forest in India: climate, fire, elephants and the evolution of life-history strategies. In: Biotic Interactions in the Tropics: Their Role in the Maintenance of Species Diversity (eds Burslem, D., Pinard, M. \& Hartley, S.). Cambridge University Press, Cambridge, pp. 510-529.

Ter Steege, H., Pitman, N., Sabatier, D., Castellanos, H., Van der Hout, P., Daly, D.C. et al. (2003). A spatial model of tree alphadiversity and tree density for the Amazon. Biodivers. Conserv., 12, 2255-2277.

Von Foerster, H. (1959). Some remarks on changing populations. In: The Kinetics of Cellular Proliferation (ed. Stohlman, F. Jr). Grune and Stratton, New York, NY, pp. 382-407. 
Webster, P.J., Holland, G.J., Curry, J.A. \& Chang, H.-R. (2005). Changes in tropical cyclone number, duration, and intensity in a warming environment. Science, 309, 1844-1846.

West, G.B., Brown, J.H. \& Enquist, B.J. (1997). A general model for the origin of allometric scaling laws in biology. Science, 276, 122-126.

West, G.B., Brown, J.H. \& Enquist, B.J. (1999). A general model for the structure and allometry of plant vascular systems. Nature, 400, 664-667.

Williamson, G.B., Laurance, W.F., Oliveira, A.A., Delamonica, P., Gascon, C., Lovejoy, T.E. et al. (2000). Amazonian tree mortality during the 1997 El Nino drought. Conserv. Biol., 14, 1538-1542.

Wright, S.J. (2005). Tropical forests in a changing environment. Trends Ecol. Evol., 20, 553-562.

Wright, S.J., Muller-Landau, H.C., Condit, R. \& Hubbell, S.P. (2003). Shade tolerance, realized vital rates, and size distributions of tropical trees. Ecology, 84, 3174-3185.

Zimmerman, J.K., Everham, E.M. III, Waide, R.B., Lodge, D.J., Taylor, C.M. \& Brokaw, N.V.L. (1994). Responses of tree species to hurricane winds in subtropical wet forest in Puerto Rico: implications for tropical tree life histories. J. Ecol., 82, 911922.

\section{SUPPLEMENTARY MATERIAL}

The following supplementary material is available online from http://www.Blackwell-Synergy.com:
Appendix S1 Derivations of tree size distributions from growth and mortality relationships.

Appendix S2 Details of the methods for fitting growth and mortality.

Table S1 Akaike Information Criteria for the phenomenological fits to the tree size distributions.

Table S2 Log likelihoods of the observed size distributions under the predictions based on growth and mortality parameters.

Table S3 Parameters of the fitted and predicted size distributions.

Figure S1 Observed, predicted and fitted tree size distributions for all sites.

Editor, Marcel Rejmanek

Manuscript received 19 December 2005

First decision made 27 January 2006

Manuscript accepted 6 February 2006 